\title{
ENVELHECIMENTO POPULACIONAL E SUAS IMPLICAÇÕES À GESTÃO DE MARKETING: UMA INVESTIGAÇÃO NO SETOR DE ACADEMIAS DE GINÁSTICAS
}

Data de submissão: $28 / 02 / 2018$ Aceite: 11/04/2018

\author{
Renata S. Bernardes Queiroz \\ Marcia Milena Pivatto Serra² \\ Emília Orsi ${ }^{3}$ \\ Marcos Rogério Mazzieri ${ }^{4}$
}

\section{RESUMO}

Este trabalho tem como objetivo analisar como as academias de ginástica estão respondendo ao fenômeno do envelhecimento populacional. Algumas pesquisas e estudos têm apontado necessidades específicas do segmento de mercado idoso. No entanto, buscou-se discutir o mercado envelhescente e a oferta de serviços esportivos e de academias para os indivíduos com mais de 40 anos, que começam a apresentar necessidades físicas e limitações associadas ao processo de envelhecimento. A abordagem da pesquisa é qualitativa descritiva e os dados foram obtidos por meio de entrevistas com proprietários ou funcionários de academias localizadas na Região Metropolitana de Campinas. A análise dos resultados indicou o reconhecimento do potencial dos consumidores mais velhos e envelhescentes, entretanto, nenhum dos entrevistados possui práticas e serviços que atendam exclusivamente às necessidades desse grupo de consumidores. Nesse contexto, a pesquisa buscou identificar os fatores e atributos mais relevantes para o fornecimento de serviços de academias para o público envelhescente, a partir do reconhecimento da oportunidade e do potencial desse mercado. O estudo apresenta algumas contribuições para a área de marketing de serviços, como também acrescenta aspectos relevantes para o desenvolvimento de negócios que buscam esse mercado potencial.

Palavras-chave: Envelhecimento, setor esportivo, marketing esportivo

\footnotetext{
1 Possui graduação em Economia pela Universidade de São Paulo, mestrado em Administração pela Universidade de São Paulo, e Doutorado em Comunicação pela Escola de Comunicação e Artes da Universidade de São Paulo. Campinas - SP - Brasil.

E-mail: resbqueiroz@gmail.com

2 Possui graduação em Bacharel em Estatística pela Universidade Estadual de Campinas, UNICAMP, mestrado em Estatística pela UNICAMP, doutorado em Demografia pela UNICAMP. Campinas - SP - Brasil. Email: marcia.serra@mackenzie.br

3 Graduação em andamento em Administração pela Universidade Presbiteriana Mackenzie, MACKENZIE. Catanduva - SP - Brasil.

E-mail: emilia.orsi@gmail.com

4 Possui graduação em Administração pela Associação Internacional de Educação Continuada, AIEC, especialização em Administração Financeira pela Fundação Getúlio Vargas, FGV, especialização em Captação de Financiamentos pela AIEC, especialização em Marketing pela FGV, mestrado em Administração pela Universidade Nove de Julho, UNINOVE e doutorado em Administração pela UNINOVE. São Paulo - SP - Brasil. E-mail: marcosmazzzieri@gmail.com
} 


\section{INTRODUÇÃO}

Nogueira et al. (2008) refletem que a população brasileira tem sofrido uma alteração na sua distribuição de idade, o aumento da longevidade já é uma realidade e indica a necessidade de se compreender, no âmbito social, o impacto do envelhecimento populacional nas esferas organizacionais e de consumo (LOCATELLI; FONTOURA, 2013).

Este presente trabalho alinha-se dentre essas iniciativas uma vez que se propõe a investigar como as empresas do setor de serviços esportivos, em especial, academias de ginásticas têm respondido ao fenômeno do envelhecimento da população brasileira.

A terceira idade é uma expressão que denomina pessoas acima de 60 anos, pois nessa idade a população, de modo geral, se aposenta marcando o início de uma nova etapa da vida (KELLY; RIBAS; COSTA, 2010). Múltiplos estudos já foram realizados para compreender os idosos, suas preferências e motivações. Entretanto, comparativamente, pouco se investiga no que tange aos adultos maduros e que ainda não atingiram a melhor idade (40 a 59 anos).

As projeções do IBGE (2013) mostram que em 2050 a população com idades entre 40 e 59 anos será a maior em relação a todos os outros segmentos etários. A essa fase etária o presente trabalho denomina "envelhescente". Termo que vem sendo empregado em artigos acadêmicos e faz uma analogia a adolescência, refletindo uma etapa de preparação para a velhice, assim como a adolescência é uma preparação para a idade adulta (LOTH; SILVEIRA, 2012; PRATA, 2006; BERLINCK, 2000).

Pessoas com mais de cinquenta anos estão cada vez mais ocupadas, representativamente mais relevantes e marcadas por características próprias, como a perda da jovialidade, o que pode influir no comportamento de consumo, valendo a pena uma investigação mais específica (LOTH; SILVEIRA, 2012).

Os debates sobre envelhecimento populacional encontram-se entre as áreas de interesse dos estudos em Administração e Marketing, mas ainda são pouco discutidos quando comparados à quantidade de grupos de pesquisa e de trabalhos publicados pelas áreas da saúde e ciências humanas não aplicadas (LOCATELLI; FONTOURA, 2013).

Por meio de meta-análise qualitativa, realizada nos anais do Encontro Nacional dos Programas de Pós-Graduação em Administração - ENANPAD - (de 1997 a 2015), em todas as seções temáticas, utilizando-se as seguintes palavras-chave: envelhecimento, envelhescente, idoso (a), velho (a), terceira idade, nota-se que o fenômeno, tem atraído, em especial, estudos na área de Marketing e Gestão de Pessoas, havendo uma concentração maior de estudos publicados nestas duas áreas.

$\mathrm{Na}$ área de Marketing há uma concentração de estudos sobre envelhecimento populacional sob a temática de comportamento do consumidor. Segundo Slongo et al. (2009), estudos sobre o envelhecimento surgem nos anos 1980, buscando aprofundar o entendimento a respeito desse público com a finalidade de propor ações de marketing diretivas.

Segundo Locatelli e Fontoura (2013) os trabalhos sobre envelhecimento publicados na área de marketing partem do entendimento de que os idosos representam um grupo com alto potencial de consumo, que dispõem de renda e tempo, e sendo heterogêneos são passíveis de serem segmentados, segundo variáveis como gênero (SLONGO et al., 2009 apud LOCATELLI; FONTOURA, 2013); classe social (BACHA; PEREZ; VIANNA, 2006; FARIAS; SANTOS, 1998; LADEIRA; GUEDES; BRUNI, 2003; UGALDE; SLONGO, 2006 apud LOCATELLI; FONTOURA, 2013); localização geográfica (AMARO; MEIRA, 2006; ANJOS NETO; SOUZA NETO; GONÇALVES, 2002; LADEIRA; GUEDES; BRUNI, 2003; LOUREIRO et al., 2003 apud LOCATELLI; FONTOURA, 2013). 
Partindo-se do pressuposto de que Marketing é um o conjunto de conhecimentos e processos de criar, comunicar, entregar e trocar ofertas que tenham valor para consumidores, clientes, parceiros e sociedade (AMERICAN MARKETING ASSOCIATION, 2013), torna-se pertinente refletir sobre como as ações e práticas de Marketing que estão ao mesmo tempo afetando e sendo afetadas pelo envelhecimento da população e, em específico, no que se refere ao setor de serviços esportivos.

$O$ esporte é uma das grandes paixões brasileiras, e segundo pesquisa do IBOPE, a maior paixão dos brasileiros com mais de 18 anos é o futebol (77\%), seguidas da cerveja (35\%), carnaval (30\%) e churrasco (20\%) (IBOPE, 2013).

O setor esportivo e o mercado de academias vêm crescendo em um ritmo intenso e coloca o Brasil como oitava potência esportiva do mundo, isso porque, nos últimos anos o setor do esporte cresceu mais que a economia do país sendo que entre 2000 e 2012 a taxa média de crescimento do PIB foi de 3,2\% e a média de crescimento do esporte foi de 6,2\%, Estima-se que a cada $R \$ 1,00$ investido em infraestrutura esportiva, $R \$ 6,50$ é investido em varejo e marketing (SPITZ, 2012). Isso faz com que haja necessidade por uma gestão especializada e qualificada por parte das pessoas que se interessam por esportes, sejam dirigentes de clubes, torcedores, empresas patrocinadoras, entre outros (TESTA, 2009).

O problema de pesquisa fica assim definido: como as academias esportivas estão respondendo ao fenômeno do envelhecimento sob a ótica da gestão mercadológica e oferta de serviços?

O objetivo é identificar os aspectos referentes ao segmento de mercado e sua necessidade mais específica, buscando sustentar as decisões mercadológicas para um público consumidor mais envelhecido.

O presente estudo se justifica na medida em que pode contribuir na área de Administração e com estudos de Marketing sobre o Comportamento do Consumidor, proporcionando maior conhecimento de como as empresas adaptam seus esforços para melhor atender esse segmento: como ele é percebido, quais suas características e especificidades principais, implicações e consequências aos esforços mercadológicos, propiciando subsídios para as organizações atuarem de forma mais consciente e planejada diante do processo de envelhecimento populacional. Une em uma mesma investigação o foco em dois aspectos importantes: 1) a gestão mercadológica num setor econômico significativo, o esportivo; e 2) sob o olhar de um público relevante e pouco estudado até o dado momento.

\section{REVISÃO DA LITERATURA}

\subsection{Marketing de serviços esportivos e academias}

Vance, Nassif e Masteralexis (2015) alegam que o Marketing Esportivo pode ser visto como um conjunto de atividades que têm o objetivo de identificar e satisfazer necessidades de consumidores dentro da área de esportes. Relatam também, que a área esportiva está relacionada não apenas a artigos esportivos (como roupas e equipamentos), mas a eventos, competições e a entidades, por exemplo, atletas, times, federações etc.

Os mesmos autores, ao mencionarem o estudo de Mullin, Hardy e Sutton (2000 apud VANCE; NASSIF; MASTERALEXIS, 2015), explicam que marcas não esportivas também podem estar associadas a esse tipo de marketing, pois utilizam o esporte para propagar sua marca, comumente tentando relacionar valores do esporte, como trabalho em equipe, superação, etc, aos valores da própria marca. Por exemplo, os patrocinadores que têm suas marcas estampadas nos uniformes dos jogadores de futebol. 
Para Mattar e Mattar (2013, p. 114) o Marketing Esportivo, nada mais é que, "uma adaptação dos conceitos de marketing à realidade particular resultante do cenário e ambiente vividos no contexto esportivo e das instituições nele atuantes". Morgan e Summers (2008, p. 07) definem o Marketing Esportivo, sob uma ótica gerencial, como uma aplicação dos quatro elementos do Mix de Marketing (4P's): Preço, Produto, Promoção e Ponto de venda, de forma específica em um contexto esportivo, todo concebido para atender às necessidades dos clientes do esporte, sejam eles consumidores individuais, praticantes de esportes ou jogadores e investidores corporativos".

Segundo a ACAD Brasil (Associação Brasileira de Academias, 2015), o brasileiro tem apresentado uma mudança de comportamento que interfere no consumo desses serviços esportivos. Se antes atividades físicas eram praticadas apenas por grandes apreciadores da boa forma física, agora a procura por qualidade de vida, saúde e bem-estar levam a uma maior diversificação do público consumidor para esse setor. Adicionalmente, Almeida (2013) detectou uma mudança de comportamento há algum tempo, dando os primeiros passos, para cada vez melhor atender os vários mercados nesse setor.

Com a busca de serviços exclusivos e personalizados dos consumidores, academias e empresas que oferecem esses serviços estão, cada vez mais, se segmentando para atender grupos específicos como o feminino, infantil, idoso etc. Nesse contexto, é fundamental entender as características dos serviços e como se diferem da oferta de produtos. Isso porque os serviços podem ser definidos como atividades econômicas, que proporcionam benefícios e agregam valor para os clientes, em tempo e lugares determinados, realizando mudanças, por meio do que os clientes desejam. Nesse contexto, as ações do marketing de serviços diferem das ações do marketing de produtos, devido às características dos serviços como intangibilidade, envolvimento do cliente no processo, variabilidade, heterogeneidade, perecibilidade, simultaneidade, dificuldade de avaliação pelos clientes, ausência de estoques, entre outras características (LOVELOCK; WRIGHT, 2009).

A intangibilidade em serviços para Fitzsimmons e Fitzsimmons (2010) e Lovelock e Wright (2009) caracteriza-se pelo fato de que o cliente não obtém a posse de algo tangível quando o recebe, entretanto na execução das atividades de serviços podem ser envolvidos alguns elementos tangíveis que auxiliam sua entrega, buscando evidenciar a qualidade obtida. Outro ponto fundamental apontado pelos autores é o fato de que as condições em que os serviços são realizados variam muito, pois ocorrem na presença e contemplam o envolvimento do cliente no processo, acarretando na variabilidade de insumos e produtos durante a execução dos serviços. Dessa forma, é difícil para as empresas manterem um controle de qualidade em suas ofertas, o que representa forte dificuldade para o processo de avaliação dos clientes (FITZSIMMONS; FITZSIMMONS, 2010).

Ainda vale ressaltar que, diferentemente dos produtos, os serviços não podem ser estocados, pois seu consumo ocorre simultaneamente no momento da entrega. Assim pode-se dizer que a perecibilidade do serviço em conjunto com o envolvimento dos clientes faz com que o tempo seja crucial para serviços. As empresas precisam levar em consideração o tempo que os clientes estão dispostos a esperar, visto que este fator é cada vez mais valorizado pelos indivíduos. Esta característica, de acordo com Lovelock e Wright (2009), torna-se um desafio para as empresas no gerenciamento de suas operações, pois em determinados momentos estas podem ter sua capacidade produtiva ociosa e em outros momentos ter níveis de demanda muito altos. Além disso, como essas atividades são baseadas em atributos de experiência e de confiança, sua avaliação torna-se mais complexa, pois os clientes só podem avaliar o processo durante ou após o consumo dos serviços, e ainda assim encontram dificuldades para julgar seu desempenho (LOVELOCK; WRIGHT, 2009). 
No ambiente competitivo em que as empresas estão inseridas atualmente, combinado à dificuldade que representa a oferta de serviços, é fundamental que as empresas compreendam o comportamento do consumidor e seu processo de tomada de decisão, buscando criar estratégias, a fim de reter e atrair clientes. O sucesso de uma empresa prestadora de serviço também depende de sua capacidade de desenvolver relações com os clientes e de prestar serviços de qualidade.

Os estudos sobre comportamento do consumidor apontam que a satisfação ocorre quando as expectativas de desempenho do cliente são atingidas ou superadas, porém, caso isso não aconteça, os clientes tornam-se insatisfeitos e suas expectativas se frustram. Estas expectativas são formadas à medida que os consumidores recebem informações de diversas fontes a respeito do produto. Dessa forma, a satisfação ou insatisfação do cliente determinarão seu comportamento futuro, definindo se estes voltarão ou não a comprar (KOTLER; KELLER, 2013).

Assim, de acordo com Blackwell, Miniard e Engel (2008), cabe às empresas compreenderem o comportamento de compra do cliente, quais são suas expectativas em relação ao produto ou serviço prestado, a fim de satisfazê-los, sendo importante considerar que diversos fatores influenciam a tomada de decisão, os quais serão abordados no próximo tópico.

\subsection{Comportamento e processo de compra de serviços esportivos e escolha de academias}

Conforme mencionado anteriormente, na prestação de serviços é importante que as empresas tenham conhecimento a respeito da necessidade dos diferentes segmentos de mercado de clientes, buscando compreender como estes reagem à entrega do serviço (LOVELOCK; WRIGHT, 2009).

O processo de compra de serviços apresentado na literatura de marketing de serviços está dividido em três etapas: pré-compra, consumo e encontro de serviços e pós-compra. A primeira etapa consiste no processo em que o consumidor identifica as alternativas, pesa os benefícios e riscos antes da tomada de decisão. Inicia-se por meio de estímulos, os quais ocorrem por meio de indícios comerciais, os quais resultam de esforços promocionais; indícios sociais, que derivam dos grupos de relacionamento do indivíduo, como amigos, família, etc.; também de indícios físicos, que são biológicos, como fome e sede (HOFFMAN; BATESON, 2003).

A próxima etapa refere-se à execução e entrega dos serviços, definida como encontro de serviços, pois o cliente interage com o fornecedor. Inicia-se com uma solicitação por meio de uma reserva, inscrição ou pedido, e após o primeiro encontro outros podem ocorrer auxiliando a tomada de decisão. Assim, a tomada de decisão na fase de encontro do serviço pode ser afetada por diversos fatores como ambientes, profissionais e serviços de suporte. (LOVELOCK; WRIGHT, 2009). Esta última etapa é considerada a mais complexa, pois consiste na experiência que ocorre por meio de um processo interativo entre o cliente, a empresa e o ambiente desta, mesmo quando o serviço é prestado a um bem físico e não diretamente à pessoa, acontecem diversas interações pessoais. Dessa forma, acredita-se que a avaliação de serviços ocorre também no momento de uso do serviço e não somente na etapa pós-compra o que permite os profissionais de marketing influenciar essa avaliação, pois podem comunicar-se com os clientes durante a ação do serviço. (HOFFMAN; BATESON, 2003).

No entanto, é mais difícil determinar e avaliar os atributos em serviços, devido às características destes como intangibilidade dos desempenhos e variabilidade. Visto que, em geral, os serviços possuem poucos atributos de procura, estando mais relacionados aos atributos de experiência e confiança, o que dificulta seu controle de qualidade. Dessa forma, os profissionais 
de marketing buscam evidenciar para os clientes os atributos de procura, como por exemplo, fornecendo experiência gratuita dos serviços e utilizando propaganda (LOVELOCK; WRIGHT, 2009).

A avaliação dos serviços é fortemente afetada pelo grau de envolvimento dos clientes no processo, pois estes interagem diretamente com os prestadores de serviço e o ambiente físico da empresa, gerando assim variabilidade na entrega dos serviços. Dessa forma, é preciso que as empresas impeçam fortes variações em suas atividades, a fim de manter um nível de qualidade constante ao longo do tempo (LOVELOCK; WRIGHT, 2009).

Garantir o sucesso das academias é preciso que estas identifiquem o que os clientes realmente querem, uma vez que as pessoas procuram por esse serviço ao identificar um problema ou uma necessidade, como perder ou ganhar peso, enrijecer ou definir músculos, melhorar a postura, pela aparência estética ou interação social. Entretanto, no contexto do envelhescente, essas necessidades são diferentes. Nesse contexto, compreender o processo de decisão dos consumidores que desejam começar a praticar exercícios físicos é fundamental para as empresas que procuram criar estratégias de marketing baseadas nos perfis dos clientes (LEITE, 2000).

Ao mapearem as necessidades por este tipo de serviço, os clientes buscam informações sobre academias e comparam-nas para a tomada de decisão, optando por aquelas que melhor atendem a suas necessidades (LEITE, 2000). Nos serviços oferecidos pelas academias, diversos atributos são relevantes na escolha dos clientes, como por exemplo, estrutura física, proximidade da academia com o local de trabalho ou residência, atendimento, horário de funcionamento e perfil dos frequentadores (CAMPOS, 2006). Além disso, os clientes exigem que as academias sejam flexíveis, tenham disponibilidade, sejam competitivas e possuam preços competitivos.

Pesquisa realizada por Moller (2014) na Região Metropolitana de Campinas, buscando mapear os principais atributos e motivações para a escolha de academia, identificou que a escoIha das academias é determinada especialmente pelos seguintes fatores: a opinião e influência de outros, preço e formas de pagamento, imagem percebida pelo cliente no atendimento, impulso (quando o indivíduo identifica-se com a academia e toma sua decisão sem maiores análises), conceito da academia (reputação), estilo e qualidade. Ainda segundo o autor, a decisão também é impactada pela vestimenta dos funcionários, a limpeza, a higienização e a decoração das academias. $\mathrm{O}$ atendimento também é um fator importante para as academias, pois os clientes precisam ser bem acolhidos e encantados, visando a conquista, retenção e/ou fidelização.

A forma como o cliente é recepcionado determina as primeiras impressões deste com a empresa. Os funcionários da recepção devem ser treinados, prezando sempre pela cordialidade no atendimento; já os professores devem contar com uma formação sólida e estarem sempre se atualizando com as tendências do mercado, sendo também importante no atendimento características, como simpatia, cordialidade, motivação, confiança e compromisso com o bem-estar dos envolvidos (MOLLER, 2014). Quanto à experiência e sua importância para a escolha de academias pode-se adicionar também o atendimento dos funcionários, o material, os equipamentos utilizados, a flexibilidade e a adaptabilidade dos serviços prestados.

Nessa pesquisa pôde-se identificar que, dos cerca de 130 respondentes, entre os principais motivos que levam os indivíduos a frequentar academias estão: os benefícios que os exercícios físicos trazem a saúde, com $92 \%$ de concordância dentre os entrevistados, $6 \%$ são indiferentes aos benefícios que os exercícios físicos trazem, sendo que apenas $2 \%$ discordam que esta seja a principal razão para frequentarem academias. Os demais motivos citados, por ordem de relevância foram: para tornar-se mais atraente, para $40 \%$ dos pesquisados, no qual $26 \%$ são indiferentes a este motivo e $34 \%$ discordam desta afirmação. Evitar a obesidade e estar fora dos padrões estipulados pela sociedade foi considerado importante para $34 \%$ dos participantes, porém 
40\% discordam ser a obesidade um dos motivos de maior relevância para frequentarem academias. A luta contra o envelhecimento foi analisada como importante fator para a prática de exercícios físicos nas academias por apenas $16 \%$ dos respondentes, sendo que, $65 \%$ discordam que esta seja a razão principal por qual frequentam academias e $19 \%$ são indiferentes. Para $26 \%$ dos respondentes as academias atuam como dose diária de injeção de ego, porém $54 \%$ discordam disso. Apenas $16 \%$ dos participantes afirmam fazer academia para se comparar a outras pessoas e se sentirem melhor, quanto à discordância dessa afirmação o percentual obtido foi de $75 \%$.

Com o intuito de compreender parte das necessidades mais específicas do segmento envelhescente e apresentar atributos de envolvimento e experiências, a segmentação de serviços esportivos e academias vem ganhando cada vez mais espaço no setor, pois os clientes buscam por serviços exclusivos e personalizados, dessa forma, algumas redes de academias tem percebido uma oportunidade para diferenciar-se do mercado de massa, focando em públicos específicos, como o público feminino, crianças e idosos.

\subsection{Serviços esportivos e academias para idosos e envelhescente}

Os envelhescentes sofrem mudanças fisiológicas e comportamentais que fazem com que esse grupo tenha necessidades específicas (RODRIGUES; DIOGO, 2000), além disso, possuem características novas e diferentes que representam um grande potencial de negócio. Já que o envelhecimento está transformando drasticamente a sociedade, a forma de conduzir o mercado também muda, abrindo infinitas possibilidades no mundo empresarial e tecnológico (IRVING, 2014).

Propagandas de algumas décadas atrás traziam idosos representados, algumas vezes, de forma preconceituosa ou estereotipada. Atualmente sabe-se que o público idoso responde as propagandas, apesar de comprarem pela qualidade, sendo pouco inclinados a comprar por impulso. Direcionando a eles o produto certo, são potenciais consumidores, pois dispõem de tempo, dinheiro e vontade de comprar (IRVING, 2014).

Os idosos de hoje não são os mesmos de gerações anteriores, tendem a ser mais ativos que seus pais. Desejam envelhecer ativamente, viajando, estudando, voltando ao mercado de trabalho, apaixonando-se e explorando a vida com seus olhos experientes. Pessoas com mais de 40 anos passaram a se preocupar mais com a saúde, atividades físicas e sociais e com o conforto, tendem a possuir uma maior renda e gastando não somente com eles, mas também com netos, pais, filhos, etc. (IRVING, 2014). A prova desta procura por melhor qualidade de vida e proatividade são os $30 \%$ de idosos matriculados em academias em todo o Brasil, dado que, há dez anos, eram apenas $5 \%$. Ou seja, quase um terço dos alunos das academias possuem mais de 60 anos representando um nicho de mercado em crescimento com perspectiva de muito retorno para o setor fitness. Os envelhescentes são também vistos com maior frequência nas academias. Uma pesquisa da American College of Sports Medicine revelou que a atividade física com sobrecarga, como a musculação, pode minimizar ou estacionar os efeitos da osteoporose, fazendo dessa modalidade a mais procurada por pessoas acima dos 50 anos (ACAD- Brasil, 2012). Essas alterações e características próprias deflagram às empresas uma necessidade de mudança e inovação nas ofertas de produtos e serviços para atender e cativar essa parte dominante da população que apresenta singularidades referentes aos fatores que influenciam na decisão de compra, já que atualmente, correspondem a aproximadamente $20 \%$ do poder de compra do país (SEGALLA; PEREZ, 2012).

Com o crescente número de produtos e marcas disponíveis, a abertura de novos mercados, novos canais de distribuição, encurtamento do ciclo de vida dos produtos e a rapidez das 
mudanças tecnológicas houve um acirramento da concorrência, tornando necessário cada vez mais informações para dar suporte para as atividades de marketing implementadas por profissionais da área. Dessa forma, compreender o comportamento do consumidor envelhescente se torna cada vez mais relevante para a sobrevivência das empresas em diferentes mercados, em especial na prestação de serviços.

Segundo Kotler e Keller (2006, p. 236) um "segmento de mercado consiste em um grupo de consumidores que possuem as mesmas preferências", essa segmentação é cada vez mais buscada, para que se possa tomar decisões mais eficazes, entendendo como esse consumidor pensa, age e decide ao comprar um produto. Kotler e Fox (2004, p.396), exemplifica que "mulheres, de meia-idade, para cursos de meio período, deverá considerar se a sua estrutura, funcionamento, recursos físicos, financeiros e humanos estarão preparados para atender essa nova clientela", ou seja, entender o seu cliente é importante para conseguir satisfazê-lo.

Muitas empresas já tratam a terceira idade como um segmento de mercado que, segundo Kotler e Keller (2006, p. 238), "é um grupo definido mais estritamente que procura por um mix de benefícios distintos". Os autores reforçam ainda que esse mercado apresenta grande potencial, no entanto é fundamental que as empresas entendam seu cliente de forma tão eficiente que estes passam a estar dispostos a pagar um preço premium pela entrega de serviços diferenciados (KOTLER; KELLER, 2006).

No que tange o mercado idoso é importante lembrar que alguns recursos sociais os ajudam a se ajustar ao ambiente para obter uma perspectiva positiva de bem-estar psicológico. Isto inclui autonomia para tarefas do dia-a-dia, bom relacionamento com outras pessoas e reconhecimento de suas limitações. Os idosos são capazes de se adaptar a situações diversas dependendo do autojulgamento do indivíduo. Quanto mais positiva a autoimagem e o reconhecimento das limitações físicas, melhor será o enfrentamento de situações difíceis (RABELO, D.F.; NERI, A.L., 2006).

A percepção positiva das limitações físicas dos idosos depende de fatores histórico-culturais e do modo como lidam com essa fase da vida. Silva, Oliveira e Rabelo (2012) observaram em uma pesquisa utilizando escala Likert ( $1=$ pouquíssimo e $5=$ muitíssimo) que a média dos idosos para "aceitação pessoal" foi de 4,2, com desvio padrão de 0,5 , ou seja, há uma alta aceitação pessoal, os idosos se aceitam e respeitam suas dificuldades e limitações.

Já Corazza (2014), em entrevista ao Portal do Envelhecimento, afirma que o idoso mudou e que, a maioria dos idosos atualmente são proativos, participativos, flexíveis e conscientes quanto à importância das atividades físicas para a qualidade de vida. Segundo o autor, os idosos passaram a acreditar muito mais no próprio potencial e não sentem mais receio de ir à academia. Além disso, o autor afirma que a motivação dos idosos para ir à academia é manter um corpo saudável e conseguir desenvolver atividades do dia a dia de maneira independente, além de ambientes novos e novos meios de se relacionar com pessoas diferentes, ou seja, buscam se realocar na sociedade.

Já o idoso busca apenas ter um corpo sadio e por isso o retorno é rápido. Ele não tem que trabalhar o visual. Para as mulheres, conseguir mexer os braços para abotoar o sutiã já é um alívio. $O$ idoso quer independência para carregar as compras e amarrar os sapatos, ter qualidade de vida (CORAZZA, 2014).

No entanto, Samulski (2009) observou que quando as pessoas chegam aos 40 e 50 anos, principalmente sem atividades físicas, sofrem muitas mudanças no corpo provocando uma mudança no autoconceito, fazendo com que o indivíduo se sinta cansado. Desse modo, diminuindo ainda mais as chances de praticar exercícios por medo de lesões, as quais acreditam que as atividades físicas poderiam causar. 
Adicionalmente, em pesquisa realizada pela ACAD (2012) em parceria com a PUC-RJ e a PUC-SP, estimou-se que 52,9\% das academias no Rio de Janeiro e $65,1 \%$ das de São Paulo ofereciam atividades específicas para idosos, sendo a musculação, o pilates e o alongamento as modalidades mais procuradas.

Na Região Metropolitana de Campinas, em estudo obtido a partir de pesquisa realizada com 15 academias, identificou-se que 25 academias (83\%) apresentaram programa específico de atividades físicas para idosos, enquanto 5 academias (17\%) não apresentaram nenhum programa específico (FRANCESCANTONIO, 2008). No entanto, o estudo não apresenta nenhum resultado associado ao mercado envelhescente, o que adicionalmente justifica o desenvolvimento de pesquisas com esse público.

Partindo-se do referencial teórico apresentado, esse trabalho pretende mapear como as academias esportivas estão respondendo ao fenômeno do envelhecimento sob a ótica da gestão mercadológica e oferta de serviços, partindo-se da identificação dos aspectos referentes ao segmento de mercado e suas necessidades mais especificas, buscando sustentar as decisões mercadológicas para um público consumidor envelhescente.

\section{METODOLOGIA}

A abordagem da pesquisa é qualitativa descritiva e os dados foram obtidos por meio de entrevistas gravadas e depois transcritas. Para participar era necessário concordar com o Termo de Consentimento Livres e Esclarecido (Apêndice A) e as questões eram semiestruturadas (Apêndice B) geradas a partir da matriz de amarração teórica. Foram entrevistados seis gestores, proprietários ou funcionários de organizações da Região de Campinas do setor de serviços esportivos. $O$ intuito era explorar o fenômeno do envelhecimento, entendendo como a organização de serviços esportivos tem atraído e atendido o público envelhescente e idoso. Os profissionais foram selecionados por disponibilidade de acesso no período da coleta de dados.

A amostra foi selecionada intencionalmente, portanto não probabilística, e por acessibilidade ou conveniência, que se encaixe no foco da pesquisa. A análise dos resultados das entrevistas foi o ponto de partida e foram entrevistados tantos indivíduos quanto foram necessários para que se atingisse a saturação teórica segundo Prado (2008): quando as entrevistas apresentam respostas similares e não se encontram mais dados adicionais que contribuam para desenvolvimento dos elementos estudados. Os dados foram transcritos e analisados por meio da técnica de análise de conteúdo, com a ajuda da matriz de amarração.

Para manter a privacidade dos entrevistados e de suas respectivas academias foi designado " $X$ " para referenciar as entrevistas e a numeração junto à letra é de acordo com a ordem de ocorrência da entrevista.

- X1- Academia localizada em Campinas-SP, oferece várias modalidades de esportes e aulas, como artes marciais diversas, musculação, spinning, glúteo, natação etc. Possui três unidades na cidade e diferentes perfis de público alvo, de acordo com a modalidade. A entrevistada era uma mulher jovem com pouco mais de dois anos de empresa e formada em Marketing.

- X2- Academia localizada em Catanduva-SP, oferece várias modalidades de dança como jazz, sapateado, aero dance, "for you" e balé, além do pilates. Seu público alvo são mulheres e crianças de classe A e B. A entrevista foi concedida pela proprietária da academia, uma envelhescente que atua no setor a mais de 40 anos e formada em educação física. 
- X3- Academia de Vinhedo-SP, oferece musculação, jiu jitsu, sanshou e zumba. Seus alunos são em sua maioria homens jovens, com exceção da aula de zumba que atrai mulheres de diferentes idades, crianças a idosas. A entrevista foi concedida pelo proprietário, 35 anos, formado em educação física e faixa preta de jiu-jitsu.

- X4- Academia situada em Campinas-SP com as modalidades: muay thai, jiu jitsu e boxe. Seu público alvo foi descrito na entrevista como "família", ou seja, homens e mulheres, jovens e envelhescentes. $O$ entrevistado era um adulto com idade entre 35 e 40 anos, faixa preta de Muay Thai há 15 anos e proprietário do estabelecimento.

- X5- Academia em Campinas-SP que oferece pilates, massagens modeladora e relaxante e drenagem linfática. Seu principal público são mulheres de 30 a 50 anos de idade seguido de idosas. A entrevista foi concedida pela proprietária, uma moça jovem formada em fisioterapia.

- X6- Academia em Campinas- SP com foco em musculação de alta performance, mas que oferece também jiu-jitsu, muay-thai e alongamento. Seus alunos são descritos como quem busca alto desempenho e muito disciplinados de maioria masculina e de diversas faixas etárias. Quem respondeu a entrevista foi um funcionário, jovem, do sexo masculino responsável pela recepção dos alunos, entre outras atividades, no período noturno. Possui, também, uma loja de suplementos no período comercial.

\section{ANÂLISE E DISCUSSÃO}

Levando em conta os relatos dos entrevistados, buscou-se entender como empresas do setor esportivo estão se comportando mediante o aumento significativo de pessoas envelhescentes, com mais de 40 anos no consumo de serviços esportivos. Quais as características e motivações que os entrevistados percebem nos envelhescentes e se direcionam de alguma maneira seu posicionamento estratégico a eles de acordo com essas percepções.

\subsection{Características do público envelhescente aos olhos dos entrevistados}

Ao se perguntar como o público envelhescente era identificado pelos entrevistados, as respostas foram diversas. Nas entrevistas 1, 2, 5 e 6 o público em questão foi definido como alguém que se preocupa com a saúde e qualidade de vida tanto de maneira preventiva tanto como para tratamento de dores e patologias comuns à idade em questão, destacada pela entrevista 5. Entretanto outras características também foram atribuídas, por exemplo, na entrevista 2 é colocado que os envelhescentes possuem "mais garra" em relação aos mais jovens, já na entrevista 6 eles são caracterizados como "mais interessados e monetizados".

X1 - [...] é um público de meia idade, que já está preocupado com um estilo de vida mais saudável que começa a treinar depois de um tempo.

$\mathrm{X} 2-[\ldots]$ as vezes uma pessoa de mais idade tem mais garra que uma pessoa mais jovem porque ela sabe da necessidade da saúde dela, coisa que o jovem não dá muita atenção. X5 - [...] as pessoas estão procurando tanta qualidade de vida eu acho que não tem algo, bom, acho que nos 40 anos já começa aparecer um pouco mais uma dor no joelho, uma dor na coluna, então você começa identificar mais dessa forma, as patologias começam a aparecer, as dores começam a aparecer um pouco mais daí elas dão um boom em torno de 50, 60 e aí vai vindo as patologias da idade mesmo, tradicional.

X6 - [...] A questão do público mais velho eu acho que eles estão tomando mais cuidado 
com a saúde sim. Eu vejo pela minha própria família. Minha mãe nunca praticou atividade física e hoje de uns anos pra cá ela vem treinando, vem fazendo e tem melhorado bastante. Ela, as amigas... e é um público que.. não dizendo só pela academia, mas pela loja [de suplementos] que eu tenho também, é um público que eu quero atingir, eu quero buscar. Porque é um público mais interessado, mais monetizado.

A fala do entrevistado 6 corrobora para os achados de Irving (2014) de que os idosos e envelhescentes são, de modo geral, monetizados e procuram por produtos e serviços para o cuidado da saúde e sinais da idade. São mais educados e influentes que seus pais na mesma idade e gastam dinheiro não apenas consigo.

$\mathrm{Na}$ entrevista 3, 4 e 6 um dos pontos destacados foi a característica física do idoso envelhescente, relatam a menor força muscular em relação aos jovens, mas que as limitações são enfrentadas de maneira positiva, mas a musculação é tratada com receio de ser usada para ficar musculoso, o objetivo dos exercícios parece estar relacionado à saúde e não à estética.

X3 - [...] Sim, visível [diferenças em relação aos mais jovens] e questão de força e tudo. Por isso tem que analisar cada um, porque também às vezes com a mesma idade tem pessoas mais envelhecidas outras um pouco melhor, mas dá pra perceber, você vê, é força, tudo é diferente, tem que ter a atenção redobrada e montar um treino de acordo com cada um. X4 - [...] Mas, perfil é totalmente diferente. É uma pessoa segura, é uma pessoa mais tranquila, uma pessoa calma, que sabe o que quer, já aceita mais. Já a pessoa nova, não. [...] O aluno velho, o aluno mais velho é mais fácil de lidar. Sobre aceitação. Sobre fidelidade, eles se identificam com a equipe. Aí é o novo e o antigo. Eles se identificam com a equipe. [...] Então, a motivação. O cara, o menino, o homem mais velho, a mulher também, ela sabe o que ela quer, ela está segura. O homem, ele sabe o que quer. Ele sabe que ele vai levar um ano para ele ficar bem, e ele segue o passo a passo. Ele aceita isso. X6 - [...] Na verdade a musculação é indicado pra qualquer faixa etária, principalmente pro público mais velho. É que geralmente eles têm um pouco de medo, aí, não quero ficar grande, não quero ficar forte.

Isso reforça a importância dos idosos se ajustarem no ambiente para obter uma perspectiva positiva de bem-estar psicológico, apontada por Rabelo e Neri (2016), que reforçam a autoimagem e o reconhecimento das limitações físicas, consequentemente, melhor será o enfrentamento de situações difíceis.

\subsection{Motivações para o consumo de serviços esportivos}

Outro ponto analisado na entrevista é, na opinião dos entrevistados, qual era a motivação do público com mais de cinquenta anos para procurar seus serviços. São destacadas motivações como o convívio social, a saúde, o tratamento de patologias ou simplesmente para ter uma atividade física.

X1 - [...]. Eles gostam de estar no meio de todo mundo e o pessoal como conversam muito com eles, eles gostam, se sentem super queridos.

X3 - [...]. Agora o resto, as pessoas de idade, já não ligam tanto pra beleza, vem por causa da saúde mesmo.

X6 [...] Mas eu acho que a grande motivação é qualidade de vida, é saúde mesmo. Não é a performance física, que em tese é o nosso foco.

X5 [...] então ele acaba vindo pra cá, por atividade física mesmo acabam vindo pro pilates, um pouco por causa de dor e um pouco por atividade física por 'ai não gosto de fazer caminhada, tenho alergia a cloro, não posso fazer natação e odeio musculação'. 
Essas respostas corroboram com Corazza (2014) que afirma que a motivação dos idosos para ir à academia é manter um corpo saudável e conseguir desenvolver atividades do dia a dia de maneira independente. $O$ autor destaca também que os idosos procuram nesses ambientes, além de um rendimento físico melhor, uma companhia, estar em ambientes novos e novos meios de se relacionar com pessoas diferentes, ou seja, buscam se realocar na sociedade.

\title{
4.3 Produtos/serviços pensados exclusivamente para o público de 50 anos ou mais
}

Apesar das empresas terem notado um aumento da procura pelos serviços por pessoas mais velhas e seu grande potencial, elas não investem nessa faixa etária, ou seja, não fazem campanhas de vendas e nem serviços próprios para atender essa demanda, apenas adaptam seus serviços, mesmo quando o maior desafio da organização é aumentar e diversificar o número de alunos.

\begin{abstract}
X1 - Olha, atualmente é ter novas adesões, é nosso maior desafio. [...], porque com todo o mercado, por conta de tudo que está acontecendo as pessoas estão cortando tudo que eles acham supérfluos, então a academia é a primeira coisa que eles acabam cortando. [...] eu posso te dizer é que a gente tem uma estrutura e a gente tem um perfil profissional técnico muito especializados pra isso, não só pra idosos, mas eles são muito bons pra atender todos os públicos, então eu consigo te falar que hoje a gente consegue atender nesse ponto, mas falar que eu estou divulgando e focando neles.... com certeza não. Então a gente não foca muito neles mas a gente tenta dar a estrutura pra eles.

X6 - [...]é um público que eu quero atingir, eu quero buscar. Porque é um público mais interessado, mais monetizado. [...] Mas eu acho que a grande motivação é qualidade de vida, é saúde mesmo. Não é a performance física, que em tese é o nosso foco.[...] É que aqui eu não tenho muita coisa. O público que eu tenho mais velho é um público da musculação. Na verdade a musculação é indicado pra qualquer faixa etária, principalmente pro público mais velho. É que geralmente eles têm um pouco de medo, ai, não quero ficar grande, não quero ficar forte.
\end{abstract}

Ao que parece os entrevistados percebem o alto potencial dos envelhescentes e manifestam desejo em atendê-los, entretanto percebem também que muitos sentem medo de usufruir seus serviços, pois receiam que a percepção de valor da academia possa não ser compatível com o que é procurado por eles.

No entanto, percebe-se forte contraste entre a percepção de valor da academia pelo consumidor e sua real motivação. Na percepção das academias, o alto desempenho físico é considerado o elemento mais importante, enquanto que a real motivação dos consumidores é a busca de saúde e qualidade de vida.

Das academias entrevistadas, apenas uma possuía aulas de hidroginástica exclusiva para idosos, nenhuma outra modalidade era destinada exclusivamente para este público. O que acontecia eram apenas adaptações de seus serviços para atendê-los, sem segmentação ou direcionamento para esse público.

As considerações apresentadas por Francescantonio (2008) são, de certa forma, questionadas neste estudo, muito embora o objetivo desta pesquisa não seja quantificar tais programas e sim entender o interesse das academias no público envelhescente.

\section{CONCLUSÃO}

Com base nos estudos realizados sobre gerenciamento de empresas no setor esportivo e comportamento de consumo dos envelhescentes e idosos, esse presente trabalho procurou responder como academias e diversas empresas desse mercado estão se comportando mediante 
o aumento significativo de pessoas com mais de 40 anos no consumo de serviços esportivos.

Com a análise das seis entrevistas, foi possível observar como os gestores das empresas viam os mais velhos. Como o alto poder de consumo dessa faixa etária que dispõe de tempo e dinheiro para consumir em diversos setores da economia.

Outro ponto a ser destacado é a ideia de que idosos sentem medo de praticar determinadas modalidades, principalmente por receio de lesões causadas pela atividade física. Entretanto alguns autores colocam que a população tem envelhecido com a consciência da importância do exercício físico na qualidade de vida e que os idosos, diferente de décadas passadas. Não se pode deixar de considerar que aqueles que ainda não se atentaram para uma vida menos sedentária passam inúmeras vezes, por medo de crítica social.

Quanto às motivações dos idosos para a procura de atividades físicas, foi destacado principalmente a saúde, além de maior independência nas atividades do cotidiano e realocação na sociedade. Já os envelhescentes buscam a preservação da autoimagem e um envelhecimento com mais qualidade de vida.

Mesmo estando cientes do envelhecimento populacional, e do potencial que este nicho de mercado oferece (idosos e envelhescentes), as academias entrevistadas não possuem práticas que atendam essa demanda. Apenas uma das academias possui aulas específicas para idosos, enquanto as outras adaptam seus serviços para atendê-los minimamente. Sendo que nenhuma delas têm os idosos e os envelhescentes como público alvo. Estas características denotam uma desvantagem competitiva já que estudos mostram que muitas empresas, dessa mesma região e mesmo a nível nacional, estão se preparando para atender esse público.

\section{REFERÊNCIAS}

Associação Brasileira de Academias - ACAD Brasil. O mercado. Disponível em: <http://www. acadbrasil.com.br/mercado.html>. Acesso em: 15 mar. 2017.

Associação Brasileira de Academias- ACAD Brasil. O mundo envelhece: Mais idosos do que crianças. O que fazer? Tem Solução? Cenário do Fitiness: o que pensam os empresários. Nov. 2015. Disponível em: <http://www.acadbrasil.com.br/revista/revista72/index.html>. Acesso em: 15 mar. 2017.

ALMEIDA, M. Segmentação no fitness. Portal Gestão Fitness. Disponível em:< http://www. gestaofitness.com.br/segmentacao-no-fitness/>. Acesso em: 28 abril. 2016.

AMERICAN MARKETING ASSOCIATION. Definition of Marketing: Revisão 2013, 2013. Disponível em: <https://www.ama.org/AboutAMA/Pages/Definition-of-Marketing.aspx>. Acesso em: 15 out. 2015,

BERLINCK, M. T. A envelhescência. Psicopatologia Fundamental, p. 193-198, 2000.

BLACKWELL, R. D.; MINIARD, P. W.; ENGEL, J. F. Comportamento do Consumidor. São Paulo: Cengage Learning, 2008.

CAMPOS, L. M. A. L. M. de. Abordagem da análise conjunta no processo decisório de compra do serviço de academia de ginástica. 2006. Dissertação (Mestrado em Administração de Empresas)Fundação Getúlio Vargas, Rio de Janeiro, 2006. Disponível em: <http://bibliotecadigital.fgv.br/ dspace/bitstream/handle/10438/4117/ACF220.pdf?sequence=>. Acesso em: 15 set. 2013. 
CORAZZA, M. A. No Auge da Carreira, Maria Alice Corazza Ensina Idosos a Malharem. PORTAL DO ENVELHECIMENTO 15 mai. 2014. Disponível em: <http://www.portaldoenvelhecimento.com/ velhices/item/2517-\%E2\%80\%9Cno-auge-da-carreira\%E2\%80\%9D-maria-alice-corazza-ensinaidosos-a-malharem>. Acesso em: 17 mar. 2017.

. Personal Trainer de idosos é uma das principais tendências do mercado, diz especialista. PORTAL DA EDUCAÇÃO FíSICA 19 jun. 2012. Disponível em: <http://www.educacaofisica.com.br/ blogs/grupos-especiais2/personal-trainer-idosos-tendencias-mercado>. Acesso em: 18 mar. 2017.

FITZSIMMONS, J. A.; FITZSIMMONS, Mona J. Administração de serviços. 6. ed. Porto Alegre: Bookman, 2010.

FRANCESCANTONIO, J. Programa de Atividade Física para Idosos nas Academias: Qual é a Realidade? Trabalho de Conclusão de Curso (TCC). UNICAMP, Campinas- SP, 2008.

HOFFMAN, D. K.; BATESON, J. G. E. Princípios de marketing de serviços: conceitos, estratégias e casos. 2.ed. São Paulo: Cengage Learning, 2003.

IBGE. Instituto Brasileiro de Geografia e Estatística. Projeção da população do Brasil por sexo e idade para o período de 1980-2050: Revisão 2013. Metodologia e resultados. Brasília, DF, 2013.

IRVING, P. H. The Upside of Aging: How long life is changing the world of health, work, innovation, policy, and purpose, 1a ed. New Jersey: Wiley, 2014.

KELLY, L. T. S.; RIBAS, J. R.; COSTA, I. S. A. Atividades Física, Educativa e de Dança: Um Estudo dos Valores dos Consumidores Idosos. In: ENANPAD, 34, 2010, Rio de Janeiro. Anais... Rio de Janeiro: ANPAD, 2010.

KOTLER P.; KELLER K. Administração de Marketing. 14ạ ed. São Paulo: Pearson, 2013.

Administração de marketing. 12ª ed. São Paulo: Pearson/Prentice Hall, 2006.

LEITE, J. A. Academias estratégias para o sucesso. Rio de Janeiro: Sprint, 2000.

LOVELOCK, C.; WRIGHT, L. Serviços: marketing e gestão. 9. ed. São Paulo: Saraiva, 2009.

LOCATELLI, P. A. P. C.; FONTOURA, D. S. Envelhecimento Populacional e os Estudos em Administração. Gestão e Sociedade, v. 7, n. 17, p. 274-300, 2013. Disponível em: <http://www. gestaoesociedade.org/gestaoesociedade/article/view/1689>. Acesso em: 30 ago. 2015.

LOTH, G. B. ; SILVEIRA, N. S. P. Estudo dos Estereótipos nos Envelhescentes Sofredores de Etarismo. In: EnEO 2012, Curitiba. Anais..., Rio de Janeiro: ANPAD, 2012.

MATTAR, M. F.; MATTAR, F. N. Gestão de Negócios Esportivos. Rio de Janeiro: Elsevier, 2013.

MICHELLI, M. A prática de retenção de clientes em academias de ginástica e de condicionamento físico localizadas em Caxias do Sul -RS. 2008. Dissertação (Mestrado em Administração) Universidade de Caxias do Sul, Caxias do Sul, 2008. Disponível em: <http://tede.ucs.br/tde_ arquivos/5/TDE-2009-03-03T053603Z-

MOLLER, L. A. S. Principais atributos considerados pelos clientes na escolha de academias de ginasticas. Trabalho de conclusão de curso de Administração. Universidade Presbiteriana Mackenzie. Campinas, 2014. 
MORESI, E. A. D. Delineando o valor do sistema de informação de uma organização. 2001. Disponível em:<http://www.scielo.br/pdf/ci/v29n1/v29n1a2.pdf>. Acesso em: 20 abr.2016.

MORGAN, M. J.; SUMMERS, J. Marketing Esportivo.São Paulo: Thomson Learning, 2008.

NOGUEIRA, S. L.; GERALDO, J. M.; MACHADO, J. C.; RIBEIRO, R. C. L. Distribuição espacial e crescimento da população idosa nas capitais brasileiras de 1980 a 2006: um estudo ecológico. Revista Brasileira de Estudos de População, São Paulo, v. 25, n. 1, p. 195-198, jan/jun. 2008.

PORTAL DA EDUCAÇÃO FÍSICA. Personal Trainer de idosos é uma das principais tendências do mercado, diz especialista. 19 jun. 2012. Disponível em: <http://www.educacaofisica.com.br/blogs/ grupos-especiais2/personal-trainer-idosos-tendencias-mercado>. Acesso em: 18 mar. 2017.

PRADO, K. P. L. A. A preferência da marca no processo de decisão de compra: um estudo exploratório no segmento de baixa renda. 2008. 332p. Tese (Doutorado em Administração). Universidade de São Paulo. São Paulo.

PRATA, M. Você é um envelhescente? Diretoria da SPRJ Diretoria da SPRJ - Sociedade Psicanalítica do Rio de Janeiro Filiada à International Psychoanalytical Association -2006/2007, p. 163, 2006.

RABELO, D.F.; NERI, A.L. Bem-estar subjetivo e senso de ajustamento psicológico em idosos que sofreram acidente vascular cerebral: uma revisão. Campinas- SP, 2006.

RODRIGUES, R. A. P.; DIOGO, M. J. D.E. Como cuidar dos idosos, (orgs.). Rio de Janeiro: Papirus, 3a ed. Coleção Viva Idade, 2000.

SAMULSKI, D. M. Psicologia do esporte: conceitos e novas perspectivas. 2 ed. Barueri: Manole, 2009.

SEGALLA, A.; PEREZ, F. Envelhecer faz bem ao Brasil. ISTO É. N 2238, 2012. Disponível em: <http:// www.istoe.com.br/reportagens/241607_ENVELHECER+FAZ+BEM+AO+BRASIL>. Acesso em: 07 out. 2015.

SILVA, L. C. C; FARIAS, L. M. B.; OLIVEIRA, T. S. de; RABELO, D. F. Atitude de idosos em relação à velhice e bem-estar psicológico. São Paulo- SP, 2012.

SLONGO, L. A.; ALBRECHT, C. F.; LAVOURAS, D. F.; ESTEVES, P. S.; BARCELOS, R. H. A moda para a consumidora da terceira idade. In: ENANPAD, 33, 2009, São Paulo. Anais ... São Paulo: ANPAD, 2009.

TESTA, A. F. Notas Sobre Gestão Esportiva. Educação Física em Revista. V. 3, N 1, 2009. Disponível em: <http://portalrevistas.ucb.br/index.php/efr/article/view/1328/1015>. Acesso em: 18 out. 2015.

VANCE, Patrícia de Salles; NASSIF, Vânia Maria Jorge; MASTERALEXIS, Lisa Pike (org.). Gestão de esporte: casos brasileiros e internacionais. 1a ed. Rio de Janeiro: LTC, 2015. recurso online 